Board of Governors of the Federal Reserve System

International Finance Discussion Papers

Number 617

August 1998

\title{
THE BUSINESS CyCles OF CURRENCY SPECULATION: A REVISION OF THE MUNDELLIAN FRAMEWORK
}

\author{
Enrique G. Mendoza and Martín Uribe
}

NOTE: International Finance Discussion Papers are preliminary materials circulated to stimulate discussion and critical comment. References in publications to International Finance Discussion Papers (other than an acknowledgment that the writer has had access to unpublished material) should be cleared with the author or authors. Recent IFDPs are available on the Web at www.bog.frb.fed.us. 


\title{
The Business CyCles of CuRRenCy SPECulation: A REVISION OF THE MUNDELLIAN FRAMEWORK
}

\author{
Enrique G. Mendoza and Martín Uribe
}

\begin{abstract}
In his seminal 1960 study on the dynamics of alternative exchange rate regimes, Robert Mundell proposed a theory of balance-of-payments crises in which speculators base their actions on the observed holdings of central bankforeign reserves. We examine the quantitative implications of this view from the perspective of an equilibrium business cycle model in which rational expectations of a devaluation are conditioned on foreign reserves. The model explains some of the empirical regularities of the business cycle associated with temporary fixed-exchange-rate regimes. In turn, these cyclical dynamics validate the agents' expectations by producing devaluation probabilities that resemble those estimated from the data. The model thus aims to explain both the real effects and the collapse of exchange-rate-based stabilizations in an unified framework.
\end{abstract}

Keywords: currency crises, balance-of-payments crises, real business cycles JEL classification code: F41

* Mendoza is a Professor of Economics at Duke University and Uribe is an economist in the International Finance Division of the Federal Reserve Board. The views in this paper are solely the responsibility of the authors and should not be interpreted as reflecting the views of the Board of Governors of the Federal Reserve System or of any other person associated with the Federal Reserve System. This paper was written for The Festschrift volume in Honor of Robert A. Mundell. 
"The confidence that once prevailed in the permanence of the existing exchange parity no longer exists...Fear of inconvertibility or devaluation often swamps the effects of small differences in rates of interest between money markets, and encourages capital outflows. But confidence is generally linked to the level of exchange reserves. Other things the same, confidence is higher the larger the central bank holdings of foreign exchange"

("The Monetary Dynamics of International Adjustment under Fixed and Flexible Exchange Rates," Robert A. Mundell, QJE, v. LXXIV, no. 2, May 1960, pp.227-257)

\section{Introduction}

In a path-breaking paper that originated in his doctoral dissertation, "The Monetary Dynamics of International Adjustment under Fixed and Flexible Exchange Rates" (QJE, May 1960), Robert A. Mundell proposed an innovative framework that was the first to attempt an explicit treatment of macroeconomic dynamics under fixed and flexible exchange rates. Using the tools from Samuelson's Foundations of Economic Analysis, Mundell established a result that is now a classic principle: a fixed exchange rate may dominate a flexible exchange rate, in the sense of exhibiting better stabilizing properties in the face of exogenous shocks, if there is a high degree of international capital mobility. The apparatus he developed to derive this result was the backbone of the Mundell-Fleming model, which remained the dominant paradigm in international macroeconomics for the next 25 years. ${ }^{1}$

${ }^{1}$ It is worth noting that Mundell's (1960) setup assumed flexible prices, in contrast with the sticky-price assumption of the classic Mundell-Fleming model. Mundell noted that price stickiness was not required by the arguments of his 1960 article. 
We argue in this paper that, in the light of the globalized economy we live in today, Mundell's article contains another pioneering contribution: the first formal dynamic analysis of currency speculation. His analysis included some of the key ingredients of the classic models of balance-of-payments crises developed much later by Krugman (1979) and Obstfeld (1986). He explicitly asked the same question that models of this kind continue to raise today: "to what extent can offsetting central bank action stabilize a system which is inherently unstable because of speculative capital movements?" (Mundell (1960), p.228). Mundell examined this question in the context of a fixed-exchange-rate economy where the investors' confidence in the currency is positively related to the central bank's holdings of foreign reserves, and studied how this affected the equilibrium determination of the interest rate and the price level. His key finding was that the dynamics of adjustment could be stable or unstable, cyclical or asymptotic depending on the relative size of two "response" parameters: (a) the parameter governing the central bank's offsetting policy response to a surge in capital outflows and (b) the parameter that determines the magnitude of speculative capital outflows in response to a decline in the level of foreign reserves. An economy with strong speculative capital flows and where the central bank is slow to offset balance-of-payments deficits would tend to exhibit unstable or cyclical dynamics, whereas an economy with the opposite features would tend to exhibit stable, asymptotic dynamics. Thus, Mundell's model can exhibit endogenous fluctuations as a result of the "fight" between the government and the private sector over the central bank's foreign reserves.

In the environment of highly restricted capital flows of the 1960s, Mundell's exploration of speculation seemed of little relevance compared to his findings regarding the stabilizing properties of fixed exchange rates. Hence, his analysis of speculative capital flows was largely 
ignored in the large literature that followed the Mundell-Fleming model. Today, however, the situation is the opposite. The case of limited capital mobility is at best a teaching tool, and perfect or near-perfect capital mobility is the framework from which academic and policy discussions start. Recurrent episodes like the collapse of the ERM in Europe, the Mexican crisis of 1994, and the recent turmoil in East Asian currency markets illustrate the key relevance of the analysis of speculative attacks in an environment of highly integrated capital markets.

This paper examines the quantitative implications of Mundell's analysis of currency speculation in the light of modern international macroeconomics. Like Mundell, we study the dynamic behavior of an economy where the central bank is "fighting" with speculators over its holdings of foreign reserves. Specifically, we analyze the dynamics of currency pegs of uncertain duration in which the probability that private agents assign to the abandonment of the fixed exchange-rate regime is a decreasing function of the stock of foreign reserves held by the central bank. By proceeding in this way, we add two important elements to Mundell's analysis. First, we consider macroeconomic dynamics and speculation within an intertemporal general equilibrium framework in which firms and households maximize their objective functions subject to welldefined budget constraints, and the government must also satisfy a well-defined budget constraint. Second, we model a world with uncertainty in which the central bank deals with private agents that formulate rational expectations. These two items, while missing from Mundell's analysis, were incorporated in several theoretical studies in the modern literature on speculative attacks (see, for example, Calvo (1987) and Obstfeld (1995)). Our aim is to build on this literature to explore the quantitative predictions of models of currency speculation under uncertainty and general equilibrium. 
Interest in our quantitative analysis is justified partly by necessity, since equilibrium models with the minimum ingredients described above are analytically untractable and leave researchers with little recourse but to use numerical methods. However, the main justification for the quantitative approach is not this theoretical argument, but the fact that one of the major challenges faced by current research on the dynamics of currency pegs is to develop models that can explain the empirical regularities associated with fixed-exchange-rate regimes. As Rebelo and Vegh (1996), Mendoza and Uribe (1997), and Uribe (1997a) showed, existing equilibrium models confront serious difficulties in explaining the large macroeconomic fluctuations observed when these regimes are in place. Moreover, a wide class of these models cannot resolve the price-consumption puzzle identified by Uribe (1997b). Namely, models in this class feature equilibrium dynamics that cannot replicate the observed co-existence of a gradual appreciation of the real exchange rate with a gradual consumption boom in the early stages of currency pegs. ${ }^{2}$

The empirical regularities typical of fixed exchange rate regimes have been widely documented (see, for example, the recent studies by Klein and Marion (1997) and Kaminsky and Reinhart (1996)). The experience of high-inflation countries that suffer from chronic failures of stabilization plans anchored on fixed exchange rates has provided particularly fertile ground for analyzing these stylized facts. Several studies, as for example Helpman and Razin (1987), Kiguel and Liviatan (1992), and Vegh (1992), have documented that the initial dynamics of exchange-rate-based stabilization plans are characterized by the following three stylized facts: the

${ }^{2}$ Models in this class include perfect-foresight models with time-separable preferences and no borrowing constraints. Some models that can resolve the puzzle have been developed recently by using preferences displaying habit formation (Uribe 1997b)) or by introducing uncertainty regarding the duration of the peg (Mendoza and Uribe, 1997). 
real exchange rate appreciates sharply, external deficits widen considerably, and output and domestic absorption boom. In addition, the historical record shows that most plans end up failing with recessions predating currency collapses, periods of stability of the real exchange rate in between periods of sharp, rapid appreciation, and a high degree of correlation between private expenditures and the real exchange rate (see Mendoza and Uribe (1997)). The data also suggest that the few plans that are successful, or seem to be successful for a number of years, are in the early stages hard to distinguish from those that fail.

In this paper, we study whether an equilibrium business cycle model driven by endogenous exchange-rate uncertainty can help rationalize these stylized facts. In addition, the process that leads to the actual collapse of fixed exchange rates is a central part of our analysis. Thus, we aim to develop a unified framework in which both the collapse of fixed exchange rates and the macroeconomic dynamics of exchange-rate-based stabilizations can be studied jointly. For the most part, research on the real effects of exchange-rate-based stabilizations has set aside the analysis of currency crashes, while at the same time research on currency crashes has abstracted from studying the cyclical dynamics that predate the crashes. For example, the large literature on "credibility" models initiated by Calvo (1986) explains the real effects of stabilization plans by studying optimal household behavior assuming a given date in which there is an exogenous and fully-anticipated collapse of the currency. Similarly, most models of speculative attacks inspired in the work of Krugman (1979) and Obstfeld (1986) explain the dynamics of reserve losses and devaluations without explaining the process that leads to exchange-rate vulnerability reflected in large external deficits or overvalued real exchange rates. Paradoxically, Mundell's (1960) model was again unique in that in contrast to the modern 
literature it was explicitly aimed at studying the overall macroeconomic effects of currency speculation. The work of Calvo (1987) is another exception that aimed to link credibility models of exchange-rate-based stabilization with models of speculative attacks.

The model examined in this paper is a dynamic, stochastic general-equilibrium model that incorporates basic features of the work of Mundell (1960) and Calvo (1987). In our model, both macroeconomic dynamics and the probability of collapse of a currency peg are determined endogenously as a rational expectations equilibrium, and the probability of devaluation is the only force driving business cycles. The model represents a two-sector small open economy in which competitive firms produce traded and nontraded goods using capital and labor, and capital is an accumulable, tradable factor of production. Households and firms have unrestricted access to a perfectly competitive world capital market. Markets for contingent claims are incomplete, so that the wealth effects of devaluation risk cannot be insured away. In this setting, the probability of devaluation acts like a stochastic tax on real balances and the returns on saving in a manner similar to the uncertainty regarding the duration of economic reforms in Calvo and Drazen (1993). ${ }^{3}$ Following Mundell's work, devaluation probabilities are conditional on foreign reserves in a manner such that as reserves fall devaluation becomes more likely to occur.

The results of our numerical analysis suggest that the model makes progress in explaining some of the key empirical regularities of exchange-rate-based stabilizations. In particular, the model can produce an endogenous time path of devaluation probabilities roughly consistent with the J-shaped hazard rate functions that have been estimated in several empirical studies (see in

${ }^{3}$ Mendoza and Uribe (1997) examined a model with this feature, but taking devaluation probabilities as exogenous and ignoring foreign reserves, so currency collapse is also exogenous. 
particular Blanco and Garber (1986) and Klein and Marion (1997)). This type of hazard function also gives rise to macroeconomic dynamics that are roughly consistent with basic features of the data, including the aforementioned price-consumption puzzle. Moreover, our model also produces results that resemble the findings of Mundell's work regarding the dynamics of adjustment in the presence of speculation. In particular, the shape of the hazard function and the characteristics of equilibrium dynamics will vary depending on the relative values of parameters that govern the sensitiveness of the investors' probabilities of devaluation to observed changes in foreign reserves and the assumed policy stance of the government.

The remainder of the paper is organized as follows. Section 2 describes the model. Section 3 characterizes rational expectations equilibria and discusses the numerical solution method. Section 4 examines the simulations of the model, and discusses the effects of varying the intensity of speculative behavior. Section 5 draws conclusions and policy implications.

\section{The Model}

\subsection{The Private Sector}

Households are infinitely-lived and maximize the following expected utility function:

$$
\begin{gathered}
E_{0} \sum_{t=0}^{\infty} \beta^{t} \frac{\left.\left[\omega\left(C_{t}^{T}\right)^{-\mu}+(1-\omega)\left(C_{t}^{N}\right)^{-\mu}\right]^{-\frac{1}{\mu}}\left(1-L_{t}^{N}-L^{T}\right)^{\rho}\right]^{1-\sigma}}{1-\sigma} \\
C\left(C_{t}^{T}, C_{t}^{N}\right)=\left[\omega\left(C_{t}^{T}\right)^{-\mu}+(1-\omega)\left(C_{t}^{N}\right)^{-\mu}\right]^{-\frac{1}{\mu}}
\end{gathered}
$$

They consume a traded good, $C_{t}^{T}$, and a nontraded good, $C_{t}^{N}$, with $1 / 1+\mu$ denoting the elasticity of substitution between traded and nontraded goods and $\omega$ the share of $C^{T}$ in consumption of $C$-the latter defined by the CES aggregator in equation (2). Households also supply labor to 
industries producing traded and nontraded goods. Labor is supplied inelastically to the industry that produces traded goods, in the amount $L^{T}$. The supply of labor to the nontraded goods industry is elastic, and hence there is a time-variant tradeoff between providing labor to the nontraded goods industry, $L_{t}^{N}$, and enjoying leisure, $1-L_{t}^{N}-L^{T}$. Leisure enters in multiplicative form in utility, with $\rho$ governing the steady-state leisure-to-consumption ratio. Utility from $\mathrm{C}$ and $\mathrm{L}$ is represented by a constant-relative-risk-aversion function, with $\sigma$ measuring both the coefficient of relative risk aversion and the inverse of the intertemporal elasticity of substitution in consumption. The parameter $\beta \in(0,1)$ is the subjective discount factor.

Households maximize (1) subject to the following two constraints:

$$
\begin{gathered}
B_{t+1}-\left(1+r^{*}\right) B_{t}+\left(C_{t}^{T}+p_{t}^{N} C_{t}^{N}\right)+I_{t}= \\
A_{t}^{T}\left(K_{t}^{T}\right)^{1-\alpha T}\left(L^{T}\right)^{\alpha T}+p_{t}^{N} A_{t}^{N}\left(K^{N}\right)^{1-\alpha N}\left(L_{t}^{N}\right)^{\alpha N}-\frac{\varphi}{2}\left(K_{t+1}^{T}-K_{t}^{T}\right)^{2}-m_{t} V_{t} S\left(V_{t}\right)+\frac{m_{t-1}}{1+e_{t}}-m_{t}+T_{t} \\
I_{t}=K_{t+1}^{T}-(1-\delta) K_{t}^{T}
\end{gathered}
$$

World asset trading is limited to one-period bonds $B$ paying the time-invariant real interest rate $r^{*}$ in units of the traded good. The uses of household income on the left-hand-side of (3) are purchases of traded and nontraded goods for consumption and investment, $I$, with $p^{N}$ defining the relative price of nontradables or the real exchange rate, and changes in bond holdings net of interest. The sources of household income on the right-hand-side of (3) are factor incomes from industries producing traded and nontraded goods (net of capital-adjustment costs, transaction costs, and changes in real money balances) and lump-sum government transfers.

Production functions are Cobb-Douglas. Capital is inelastically supplied to the nontraded sector in the amount $K^{N}$ and faces a zero depreciation rate. Capital in the traded sector, $K^{T}$, is a 
traded good and depreciates at rate $\delta$. Capital-adjustment costs distinguish financial from physical assets to prevent excessive investment variability as in Mendoza (1995). Real money balances, $m$, are measured in terms of traded goods and enter the model as a means to economize transaction costs (as in Greenwood $(1983,1984)$ and Kimbrough (1986)). Transactions costs per unit of private absorption are given by $S$, which is a convex function of expenditure velocity $V=\left(C^{T}+p^{N} C^{N}+I\right) / m$. We assume that PPP in tradable goods holds and that foreign prices are constant, so $e$ represents both the inflation rate of tradables and the depreciation rate. $T$ is a lump-sum transfer from the government.

\subsection{Government Policy}

A key feature of equilibrium models of currency crises is that they incorporate explicit relationships linking fiscal and exchange-rate policies. In our case, there are nontrivial considerations in this regard that result from the probabilistic setting with incomplete markets we propose. The policy regime in our model is described as follows:

\subsubsection{Exchange Rate Policy}

The exchange-rate policy we study is an exchange-rate-based stabilization program of uncertain duration. Specifically, we assume that before period zero the economy was in a "sustainable" exchange rate regime with a constant rate of depreciation equal to $e^{h}>0$. This regime was "sustainable" in the sense that $e^{h}$ is consistent with a stationary equilibrium of the model, as described in the next section. At $t=0$, the government announces and implements a currency peg, so that $e_{0}=0$. As long as the peg lasts, agents attach a time-dependent, conditional probability to its collapse denoted by the hazard rate $z_{t} \equiv \operatorname{Pr}\left[e_{t+1}>0 \mid e_{t}=0\right]$, for $\mathrm{t} \geq 0$. Devaluation is 
assumed to be an absorbent state, so $\operatorname{Pr}\left[e_{t+1}>0 \mid e_{t}>0\right]=1$, and thus there is a date $J$ in which exchange-rate uncertainty ends and there is a devaluation with probability $1 .^{4}$

We consider a functional form for $z_{t}$ that is similar to those assumed in empirical studies of the collapse of currency pegs based on logit models (e.g., Klein and Marion (1997)):

$$
z_{t}=\frac{\exp \left[\Gamma+\frac{\mathrm{B}}{\left.\left(\frac{R_{t-1}}{Y_{t-1}}\right)-\left(\frac{R}{Y}\right)^{c r i t}\right]}\right.}{1+\exp \left[\Gamma+\frac{\mathrm{B}}{\left(\frac{R_{t-1}}{Y_{t-1}}\right)-\left(\frac{R}{Y}\right)^{c r i t}}\right]} \text { for } 0 \leq t<J-1 \text {, and } z_{t}=1 \text { for } t \geq J-1 \text {. }
$$

In this expression, $R$ represents central bank holdings of interest-bearing foreign reserves, $Y$ is the economy's aggregate output, and $B$ and $\Gamma$ are exogenous parameters. Thus, the probability of devaluation is a function of the observed gap between the lagged reserves-to-GDP ratio and a minimum critical value of this ratio. By conditioning expectations of currency collapse on foreign reserves we aim to capture the crucial feature of Mundell's (1960) analysis, in which a decline in reserves triggers speculative capital outflows. ${ }^{5}$ We also specified (5) to make our model consistent with Krugman-style models of speculative attacks: if at any date $t$ between 0 and $J-1$ the ratio $R / Y$ hits the critical level, a balance-of-payments crisis occurs with probability 1 in period $t+1$. The parameters $\mathrm{B}$ and $\Gamma$ will be set so as to allow the model to mimic time paths of devaluation probabilities estimated in the empirical literature, as discussed later in the

${ }^{4}$ We show in Mendoza and Uribe (1997) that this assumption could be changed with little effect on the numerical results for the assumption that at $J$ there is a devaluation with positive probability, and after that date there is no currency uncertainty.

${ }^{5}$ Note that this framework can be easily extended to condition $z_{t}$ on other key predictors of currency collapses identified in the recent empirical literature. 
calibration section. The parameter B will also allow us to compare the implications of our model with Mundell's findings, since B reflects the speculators response to changes in reserves.

The last element of exchange-rate policy is the response to a currency crisis. When the currency peg collapses, there is a switch to a deterministic environment in which the exchange rate depreciates at a constant rate. We follow the typical assumption of the credibility literature that collapse implies a return to the same high rate of inflation and depreciation that reigned before the stabilization plan was implemented, $e^{h}$. Hence, the post-collapse depreciation rate is fixed for all devaluation states of nature at any date $t$. Since the depreciation rate acts like a distortionary tax in our model, this assumption plays a key role in ensuring that distortions affecting private-sector behavior are limited only to those related to the uncertainty regarding the duration of the peg, and not to the post-collapse realization of the depreciation rate. Naturally, since this depreciation rate must be "sustainable," as it was prior to the implementation of the stabilization plan, the collapse of the peg must be accompanied by a state-contingent adjustment in fiscal policy, as we clarify next.

\subsubsection{Fiscal Policy}

The linkage between exchange-rate policy and fiscal policy in this model is captured by the following government budget constraint:

$$
G_{t}+T_{t}+R_{t+1}=m_{t}-\frac{m_{t-1}}{1+e_{t}}+m_{t} V_{t} S\left(V_{t}\right)+(1+r *) R_{t}
$$

The government undertakes unproductive expenditures $G$, holds foreign reserves, issues money, and makes transfer payments to households, all in units of traded goods. Both seignorage and 
transactions costs are assumed to be part of government revenue. ${ }^{6}$ During the currency peg, $G$ and $T$ are fiscal policy choices governed by the rules defined below, and the dynamics of $m$ and $V$ reflect optimal plans of the private sector that are fully accommodated by the central bank. It follows, therefore, that while the peg is in place (6) determines the evolution of foreign reserves (i.e. the balance of payments) so as to satisfy the government budget constraint.

Fiscal policy is assumed to follow three rules. First, the government allocates its revenue from seigniorage and transactions costs exclusively to finance its unproductive expenditures: ${ }^{7}$

$$
G_{t}=m_{t}-\frac{m_{t-1}}{\left(1+e_{t}\right)}+m_{t} V_{t} S\left(V_{t}\right)
$$

This rule, in conjunction with the assumption of incomplete insurance markets, implies that the model features state-contingent, fiscal-induced wealth effects similar to the ones we examined in Mendoza and Uribe (1997) for currency pegs of uncertain duration in a setting with exogenous probabilities of collapse, thus making the results of both studies comparable. In addition, this rule allows us to develop a tractable extension of the solution method we proposed in that work to the case of endogenous probabilities studied here.

The second fiscal rule dictates that, while the currency peg is in place, total government

$$
e_{t}=0 \quad \Rightarrow \quad G_{t}+T_{t .}=\kappa\left(G_{-1}+T_{-1}\right) \text {. }
$$

outlays are constant and equal to a fraction $\kappa^{t}$ of their pre-stabilization level:

${ }^{6}$ The term $m_{t} V_{t} S\left(V_{t}\right)$ in (6) can be interpreted as profits of government-owned banks. However, since they will be used only for unproductive government purchases, we could also assume that transaction costs are simply a deadweight loss.

${ }^{7}$ Mendoza and Uribe (1997) showed that a model in which seigniorage and transaction costs are rebated to households as lump-sum transfers fails to account for key features of the data. Moreover, the analytical work of Calvo and Drazen (1993) and Helpman and Razin (1987), as well as our review of Mexican fiscal policy during the 1987-94 exchange-rate-based stabilization (which is the benchmark for the calibration of the model) suggest that the case without rebates is perhaps more realistic. 
Hence, (8) states that while the exchange rate remains fixed, any changes in $G_{t}$ implied by (7) induce an offsetting adjustment in $T_{t}$ so as to ensure that total outlays remain constant. This rule ensures that the time path of reserves during a currency peg reflects only adjustments in the velocity of circulation of money and in money demand, and is not driven by arbitrary changes in the time path of government outlays. This is simply a generalization of a feature typical of models of currency crises. In Krugman (1979) or Calvo (1987), for example, government outlays are kept constant at the level they had before the peg began, and the focus is on determining the endogenous date in which reserves are depleted down to the critical level triggering a currency collapse. This scenario is included in our model (since $\kappa=1$ is not ruled out), but we also allow for the option that some fiscal adjustment may accompany the introduction of the peg. The size of this initial fiscal adjustment will be a key determinant of the date of currency crashes.

The third fiscal rule describes the behavior of lump-sum transfers after the collapse of the peg, and is implied by the previous rules in conjunction with the need to enforce intertemporal government solvency. To make the constant post-collapse depreciation rate $e^{h}$ "sustainable" regardless of the date in which collapse occurs, we allow for state-contingent adjustments in lump-sum transfers that ensure that $\lim _{t \rightarrow \infty}\left(1+r^{*}\right)^{-t} \mathrm{R}_{t}=0$. These adjustments in transfers, together with (6) and (7), ensure that as of $\mathrm{t}=0$ the present value of transfers equals $\left(1+r^{*}\right) R_{0}$.

It is instructive to compare our fiscal and exchange-rate policy regime with the one assumed in Calvo's (1987) perfect-foresight equilibrium model of balance-of-payment crises. In Calvo's regime, government outlays take the same value before and after the collapse of the peg, and fiscal solvency is maintained through an endogenous increase in the depreciation rate at the 
time the peg is abandoned. ${ }^{8}$ In contrast, in our regime the abandonment of the peg is accompanied by an exogenous increase in the depreciation rate that is constant across states of nature, and fiscal solvency is maintained via endogenous, state-contingent adjustments of government outlays. Under perfect foresight, both regimes are closely related. In fact, they induce similar dynamics if we consider a deterministic version of our model in which the postcollapse depreciation rate is set at a value such that no post-collapse fiscal adjustment is required. However, under uncertainty the two regimes are quite different. The reason is that our regime uses non-distorting, state-contingent lump-sum transfers to make the post-collapse depreciation rate independent of the date in which the program is abandoned. In Calvo's regime, on the other hand, uncertainty would imply that the rate of depreciation after the collapse varies with the duration of the program, which would create an extra distortion affecting the nominal interest rate and through it all endogenous real variables of the model. ${ }^{9}$

\section{Equilibrium and Numerical Solution}

\subsection{Rational Expectations Equilibrium}

The first-order conditions that characterize the households' optimal choices in this model are identical to those obtained in Mendoza and Uribe (1997). Hence, we limit the discussion here to a brief description of their implications for macroeconomic dynamics. The model

${ }^{8}$ Three other important differences between our model and Calvo's are: (a) in Calvo's model government outlays are only lump-sum transfers, which rules out the fiscal-induced wealth effects of our model, (b) in Calvo's model money velocity is constant while in our model it is a decreasing function of the nominal interest rate, and (c) our model allows for changes in the depreciation rate to affect labor supply and capital accumulation, while in Calvo's endowment-economy model these changes can only affect consumption.

${ }^{9}$ Note that this key difference between the two approaches would still be present even if we altered our model to bring it closer to Calvo's by considering an endowment economy in which seigniorage and transaction cost revenue are fully rebated to households. 
embodies three atemporal and three intertemporal optimality conditions. The three atemporal conditions equate: (a) the marginal utility of consumption of the numeraire good $C^{T}$ with the marginal utility of wealth adjusted for the monetary distortion (with the latter as an increasing function of the nominal interest rate), (b) the marginal rate of substitution between $C^{T}$ and $C^{N}$ with the corresponding relative price, and (c) the marginal disutility of labor in the nontradables sector to its marginal product, which is equal to the real wage. The three intertemporal conditions are Euler equations that equate the marginal costs and benefits of sacrificing a unit of tradables consumption and investing it in each of the three assets available in the economy: foreign bonds, real balances, and physical capital.

To study how exchange-rate uncertainty distorts the real economy, it is useful to examine the Euler equation for accumulation of real money balances, which can be re-written as follows:

where $\lambda^{H}$ and $\lambda^{L}$ represent the marginal utility of wealth in the high- and low-depreciation states of nature, respectively. The equation assumes that the peg is in place in period t. Equation (9) shows that $e^{h}$ is a tax on real balances that operates exactly as in perfect-foresight credibility models. The probability of devaluation plays a similar role, but in the form of a stochastic tax.

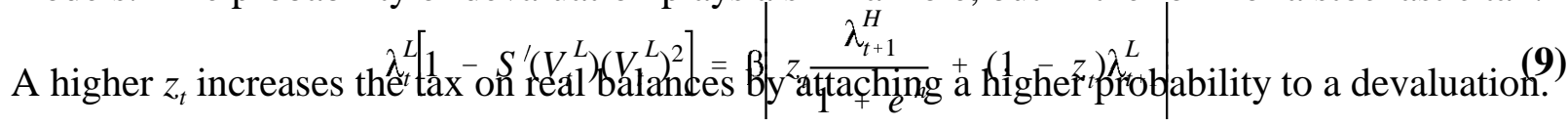
Through the transaction costs technology, the intertemporal distortions induced by exchange rate uncertainty on money demand are transmitted into the real sector of the economy. For any period $t$ in which the peg is expected to survive into period $t+1$ with some positive probability, agents have incentives to overspend relative to their long-run spending plans. This is 
because today's tax on real balances, which, loosely speaking, is given by the expected rate of devaluation in period $t+1$, is lower than the long-run tax on real balances, which, because the peg is expected to be abandoned with probability one at some point in the future, is given by $e^{h}$.

However, today's spending is smaller than it would be if households knew with certainty that the peg would survive until period $t+1$. Thus, if when period $t+1$ arrives the stabilization program is not abandoned, agents feel (ex post) that they underspent in period $t$.

The model also differs in a critical way from a perfect foresight setting, or from a stochastic setting with complete insurance markets, in that the valuation of wealth is contingent on the state of nature. If seignorage and transaction costs were fully rebated to the public in a lump-sum fashion, the real distortions would be limited to the intertemporal substitution effects discussed above. By contrast, when government revenue is used to finance unproductive expenditures, each period that the currency peg survives, permanent income rises by the amount of the foregone unproductive expenditures that high inflation could have financed.

In addition to distorting consumption, exchange rate uncertainty distorts investment and labor. The model features a direct distortion on investment that arises even under perfect foresight (see Uribe (1997)) and produces both transitional and long-run effects: A permanent disinflation induces a long-run increase in domestic physical capital by cutting transaction costs, thus reducing the wedge between the rate of return on investment in domestic physical capital and the rate of return on foreign assets. Exchange rate uncertainty (under incomplete financial markets) adds indirect investment distortions because the marginal utility of wealth is statecontingent, and because the probability of devaluation acts as a random tax on capital income at the rate $z_{t}$. The labor market is distorted because the distortions on consumption and wealth shift 
the supply of labor. The net effects of these distortions affect factor payments and allocations, and hence the household's wealth.

In order to define a rational expectations equilibrium, note that the time path of devaluation probabilities specified in (5) is endogenous and must be determined simultaneously with the equilibrium allocations and prices. Given a time path of devaluation probabilities between dates 0 and $J$, the model can be solved to yield particular paths for optimal statecontingent plans of the private sector. Taking the optimal plans for $m$ and $V$, and the fiscal policy rules, one can compute the dynamics of reserves via equation (6). However, the given path of devaluation probabilities will only be consistent with a rational expectations equilibrium if the optimal plans that they support yield dynamics of reserves via (6) that produce an identical time path of devaluation probabilities when those dynamics of reserves are passed through (5).

A rational expectations equilibrium for this model consists therefore of intertemporal sequences of allocations and prices, and a time path of devaluation probabilities, satisfying the following conditions: (a) the household's optimality conditions, (b) the market-clearing conditions for traded and nontraded goods, (c) the intertemporal government budget constraint, and (d) the consistency condition that equilibrium dynamics of reserves resulting from (6), for a given sequence of devaluation probabilities $Z \equiv\left\{z_{0}, \ldots, z_{J-1}\right\}$, must produce the same sequence $Z$ when used to compute the time path of devaluation probabilities via (5).

The nature of the policy experiment we posed implies that in the long run the rational expectations equilibrium always converges to the stationary state of a deterministic setting with a constant rate of depreciation $e^{h}$. Hence, our experiment begins and ends in well-defined, deterministic stationary equilibria compatible with $e^{h}$. The steady-state equilibrium conditions 
that characterize this outcome, and the corresponding implicit connection between $e^{h}$ and the stance of fiscal policy, can be illustrated easily in a one-good version of the model in which labor supply is inelastic. In this case, the following conditions characterize a stationary equilibrium:

$$
\begin{gathered}
A \gamma\left(\frac{C / Y}{m / Y}\right)^{1+\gamma}=\frac{\left(1+e^{h}\right)\left(1+r^{*}\right)-1}{\left(1+e^{h}\right)\left(1+r^{*}\right)} \\
\frac{C}{Y}=1+r^{*}\left(\frac{R}{Y}+\frac{B}{Y}\right)-\frac{G}{Y} \\
\frac{G}{Y}=\left(\frac{m / Y}{C / Y}\right) \frac{C}{Y}\left(\frac{e}{1+e}\right)+\frac{C}{Y}\left[A\left(\frac{C / Y}{m / Y}\right)^{\gamma}\right] \\
(1-\alpha) A\left(\frac{K}{L}\right)^{-\alpha}=\left(r^{*}+\delta\right) h\left(\left(1+e^{h}\right)\left(1+r^{*}\right)\right)
\end{gathered}
$$

where $h(\cdot)=1+S(\cdot)+V^{\prime}(\cdot) S(\cdot)$. Notice that this system is expressed in terms of output shares to be consistent with the calibration exercise of Section 4. We also adopted from the next section the exponential transactions costs technology $S=A V^{\prime}$.

The steady-state system (10)-(13) features the common problem of open economy models with standard preferences that the steady-state foreign asset position is typically dependent on initial conditions, and hence can only be determined by solving the model's dynamics (see Mendoza and Tesar (1998)). As in Mendoza and Uribe (1997), we assign a value to the postcollapse level of consumption, and solve the model's dynamics backwards to fix the initial foreign asset position consistent with that terminal condition. Given the initial asset position and 
the fact that $e^{h}$ is exogenous, it follows that in the pre-stabilization equilibrium (10)-(12) is a three-equation system in the variables $(C / Y),(m / Y)$, and $(G / Y)$, with $(13)$ determining the steadystate capital-output ratio (and hence the level of output given the Cobb-Douglas technology). It also follows trivially from (12) and the steady-state government budget constraint that in the steady state transfers must be set to rebate the interest income on foreign reserves: $T=r^{*} R$.

The need for the state-contingent adjustments in $G$ and $T$ that make $e^{h}$ sustainable regardless of the date of the currency collapse can now be easily explained. Given the functional forms we chose, it follows from the above discussion that, everything else constant, there are unique values of $G$ and $T$ that solve the deterministic steady state system for a given $e^{h}{ }^{10}$ The introduction of the peg sets the model's dynamics in motion since the steady-state conditions will no longer hold. Every period during the peg there is some chance that the rate of depreciation is reset to $e^{h}$ and the economy becomes deterministic. However, each date that this can happen the initial conditions (i.e. the values of $B, R$ and $K$ at the date of collapse) would differ, and hence since the steady-states of $R$ and $B$ depend on initial conditions, the model could not support the same $e^{h}$ constant across states of nature unless there is a state-contingent adjustment of fiscal policy. As noted earlier this is done by assuming that state-contingent lump-sum taxes or transfers ensure that reserves satisfy the transversality condition. Despite this adjustment, the fact that the same $e^{h}$ is maintained across states of nature only guarantees that the long-run capital stock, output, and money velocity are independent of the date the currency collapse (as follows from (10) and(13)). The stationary equilibria of consumption, real money balances, and

${ }^{10}$ Calvo (1987) suggested that there is a risk of obtaining multiple solutions for long-run monetary equilibria using interest-elastic money demand. However, we have ample numerical evidence showing that this is generally not the case with the functional form $S=A V^{\prime}$. 
government purchases will still vary depending on the overall net foreign asset position (i.e.

$R+B$ ) to which the economy converges from each possible devaluation date. Moreover, once the nontradables sector and endogenous labor supply are reintroduced into the model, the steadystate value of output would also differ.

\subsection{Numerical Solution Method}

The algorithm that solves for the equilibrium of this model extends the one used in our previous work on exchange-rate-based stabilization with exogenous devaluation probabilities. The appendix to Mendoza and Uribe (1997) provides details on the latter. The algorithm of that paper can be thought of as a subprogram that yields equilibrium dynamics of macroeconomic aggregates for a given $Z$. In this paper, the solution is more complex because $Z$ is endogenous. We solve the model using the following iterative procedure:

(1) Fix the values of parameters for preferences, technology, the hazard rate function, the maximum duration of exchange-rate uncertainty, $J$, the post-collapse constant depreciation rate, $e^{h}$, the initial and critical reserve-to-GDP ratios, $R_{d} Y_{0}$ and $(R / Y)^{\text {crit }}$, and the fiscal adjustment parameter $\kappa$.

(2) Start with a guess for the hazard function, $Z^{0}$, and use the subprogram from Mendoza and Uribe (1997) to compute equilibrium dynamics as if the hazard function were exogenous.

(3) Use the sequence of reserves-to-GDP ratios implied by step (2) to construct a new hazard function, $Z^{1}$, using equation (5). If this hazard function coincides with $Z^{0}$, then a rational expectations equilibrium has been found, else perform step (2) using $Z^{l}$ as the new guess. The subprogram that computes equilibrium dynamics for a given $Z$ takes advantage of the fact that at any date $t>0$ there are only two possible realizations of $e_{t}: 0$ or $e^{h}>0$. Since the state 
$e_{t}=e^{h}$ is absorbent, in each date macroeconomic aggregates can either: (a) follow the optimal state-contingent path corresponding to the state in which $e_{t}=0$; or (b) switch to the perfectforesight path corresponding to the constant rate of depreciation $e^{h}$. The subprogram follows an iterative, backward-recursion strategy. Given $Z$ and $J$, and an assumed post-collapse stationary equilibrium for the state variables $K$ and $B$, the model features well-defined state-transition probabilities and terminal conditions, so that paths (a) and (b) can be solved by backward recursion. If these paths yield initial values for the state variables that are not the same as those compatible with the values set in the calibration, the terminal conditions are updated and the solution repeated until it converges.

Note that, while the maximum duration of the currency peg $(J)$ is exogenous, this does not imply that the date of the speculative attack is necessarily exogenous. Nothing rules out that, for a given set of parameter values and policy choices, reserves can reach the critical level before period $J$, so a speculative attack may occur with probability 1 before date $J$, and the date of that attack is endogenous to the model's dynamics. Similarly, the value of $J$ can be set very high if one desired to examine the implications of a longer horizon for currency risk -- in Mendoza and Uribe (1997) we show that, when $Z$ is exogenous, this is not very important for the predictions of the model in the initial stages of the currency peg

\section{Calibration and Numerical Simulations}

\subsection{Calibration}

The model is calibrated to mimic some key aspects of Mexico's exchange-rate-based stabilization plan of 1987-94 following Mendoza and Uribe (1997). 
a) Financial Sector: The transaction costs technology is assumed to adopt the form $S\left(V_{t}\right)=A V_{t}^{\gamma}$, so that the equilibrium condition for accumulation of money balances implies an implicit money demand function $V_{t}=\left(i_{t} / 1+i_{t}\right)^{1 /(1+\gamma)}(\gamma / A)^{-1 /(1+\gamma)}$, where $i$ is the nominal interest rate. This function is calibrated to M2 money demand in México, given strong empirical evidence in favor of a loglinear relationship between $m$ and $i / 1+i .^{11}$ The coefficient $-1 /(1+\gamma)$ is the elasticity of money demand with respect to $i /(1+i)$, estimated at -0.15 , so $\gamma=5.66$. The scale parameter $A$ is set so that the high-inflation, pre-stabilization steady state mimics Mexico's M2/GDP ratio (31.8 percent on an annual basis) and nominal interest rate (177 percent annually) at end-1987. The steady-state money demand equation is then solved for $A(A=0.19)$.

b) Preferences and Technology: The risk aversion coefficient is set at $\sigma=5$, which is the lowerbound of the GMM estimates obtained for Mexico by Reinhart and Vegh (1995) using quarterly data for the period 1981-1991. Other preference and technology parameters are taken from the developing country model calibrated in Mendoza (1995) and are set as follows: $\rho=0.786, \omega=0.5$, $\mu=-0.218 \alpha T=0.42, \alpha N=0.34$ and $\delta=0.1 . \varphi=0.06$ is set to mimic the standard deviation of Mexican investment using also Mendoza (1995). Finally, we assume $\beta=\left(1+r^{*}\right)^{-1}$ with $r^{*}$ set at 6.5 percent per annum, which corresponds to the average real rate of return on equity in the U.S. in the period 1948-1981 reported by King, Plosser, and Rebelo (1988).

c) Balance of Payments and Fiscal Policy: The initial and critical values of the ratio of foreign reserves to gross domestic product are calibrated to mimic, respectively, the values observed at the beginning and at the end of the Mexican stabilization plan. The initial ratio (which uses gross reserves as of end-February 1988, when the exchange rate was initially fixed) was 7.1 percent in

\footnotetext{
${ }^{11}$ See Calvo and Mendoza (1996) and Kamin and Rogers (1996).
} 
annual terms. The final ratio, which uses gross reserves in November, 1994, was 2.8 percent also in annual terms. Notice that, strictly speaking, the final ratio corresponds to reserves in the period just before the devaluation. The pre-stabilization and post-collapse depreciation rates are both set to $e^{h}=27$ percent at a quarterly frequency, to reflect Mexico's inflation rate at the end of 1987 (which was 160 percent on a twelve-month basis). We also set $J=24$ to reflect the fact that currency collapse has coincided with the end of the six-year presidential terms in Mexico in 1976, 1982 and 1988.

Given the above parameter values and functional forms, a system analogous to (10)-(13), expanded to re-introduce nontraded goods and endogenous labor supply, is solved to determine the values of all endogenous variables in the pre-stabilization steady-state. These include the pre-stabilization steady-state values of seignorage and transaction costs revenue, government purchases and transfers, so that the pre-stabilization amount of government outlays $\left(G_{-1}+T_{-1}\right)$ can be determined.

The parameter $\kappa$, which measures the magnitude of fiscal adjustment during the peg as a fraction of $\left(G_{-1}+T_{-1}\right)$, is calibrated by requiring that in the benchmark parameterization $(R / Y)$ hits the critical level at date $J-2$ if the peg is in place at that point. This requirement implies $\kappa=$ 0.133 , which means that when the stabilization program is announced the government tightens fiscal policy sharply to reduce total outlays by 87.7 percent. The resulting path of foreign reserves implies that in the benchmark case, if the peg survives until period $J-2$, then in period $J$ 1 agents expect it to collapse in period $J$ with probability 1 both because $J$ is the assumed 
maximum duration of the program and because reserves just hit their critical level one period earlier. $^{12}$

Determining the value of $\kappa$ that satisfies these conditions requires a slight extension of the solution method. In particular, we use the following iterative procedure:

(1) Start with an initial guess, $Z^{0}$.

(2) Obtain a rational expectations equilibrium given $Z^{0}$ using the subprogram described in Mendoza and Uribe (1997).

(3) Compute $\kappa^{0}$ as the solution to the difference equation $R_{t+1}=\left(1+r^{*}\right) R_{t}+S R_{t}+T C_{t}-\kappa^{0}\left(T_{-1}+G_{-1}\right)$, with initial condition $R_{0}=\left(R_{\delta}\left(Y_{0}\right) Y_{0}\right.$ and terminal condition $R_{J-2}=(R / Y)^{c r i t} Y_{J-2}$, where $S R_{t}$ and $T C_{t}$ are short for seignorage revenue and transaction costs, respectively. This equation results from combining equations (7) and (8). The solution takes the form: ${ }^{13}$

$$
\kappa^{0}=r^{*}\left[\frac{\left(\frac{R_{0}}{Y_{0}}\right) Y_{0}\left(1+r^{*}\right)^{J-2}+\sum_{j=0}^{J-3}\left(1+r^{*}\right)^{J-3-j}\left(S R_{j}+T C_{j}-\left(\frac{R}{Y}\right)^{c r i t} Y_{J-2}\right)}{\left(G_{-1}+T_{-1}\right)\left(\left(1+r^{*}\right)^{J-2}-1\right)}\right]
$$

Note that all the terms on the right-hand-side of (14) are provided either in step (2) or by the solution of the pre-stabilization steady-state. Once $\kappa^{0}$ has been obtained, a series for foreign reserves can be constructed using the above difference equation.

${ }^{12} \mathrm{We}$ show in the simulation results that under alternative parameter configurations, particularly as $\kappa$ and $\mathrm{B}$ change, the peg may endogenously terminate before period $J$.

${ }^{13}$ Note that the necessary fiscal adjustment is higher (i.e., $\kappa^{0}$ is smaller) the higher the prestabilization level of government outlays, the higher the critical level of foreign reserves, the lower the initial level of reserves, and the lower the level seignorage revenue and transaction costs. 
(4) Construct a new hazard function, $Z^{1}$, by passing the time path of reserves from step (3) through equation (5). If $Z^{1}$ equals $Z^{0}$, then a rational expectation equilibrium has been found; otherwise, perform steps (2) and (3) using $Z^{l}$ as the guess. Continue this procedure until the hazard function converges. The value of $\kappa$ resulting from step (3) in the last iteration is the one used in the benchmark calibration of the model.

\section{d) Parameters of the Hazard Rate Function}

We parameterize the hazard rate function starting from the premise that the model ought to mimic devaluation probabilities that have been estimated in the empirical literature. Recent empirical evidence yields one robust prediction: devaluation probabilities under currency pegs evolve as J-shaped curves over time. The devaluation probability is decreasing after a peg is introduced, and eventually becomes increasing and higher than when the peg started.

Ample evidence in favor of J-shaped devaluation probabilities has been found both in country-specific studies based on models of speculative attacks as well as in cross-country studies of the determinants of exchange-rate vulnerability. For example, Blanco and Garber (1986) estimated devaluation probabilities for the Mexican peso in the six years before the devaluations of 1976 and 1982 based on a Krugman-style model of balance-of-payment crises and an econometric model of Mexican money demand. These authors estimated a probability of collapse of 0.2 early in 1977 , declining to near zero in about a year, rising slowly in 1978-79, and rising rapidly to about 0.3 before the collapse. These results are qualitatively consistent with the findings of Goldberg (1994) who also studied Mexico but extended the sample to include the 1980-86 period. Klein and Marion (1997) use a logit method to identify factors that influence the duration of currency pegs in a panel of monthly data for 17 countries over the 1957-91 period. 
They find strong evidence showing that sharp real appreciations and losses of foreign reserves predate devaluations and that devaluation probabilities are J-shaped. Probabilities of collapse one month before a devaluation are as high as 0.89 , with $1 / 10$ of the estimates higher than 0.55 . Frankel and Rose (1996) and Kaminsky and Reinhart (1996) provide further support for the finding that real appreciation and reserve losses are key predictors of currency crises.

In view of the fact that most of the empirical literature (except Klein and Marion) does not yield direct estimates of the parameters of hazard rate functions like (5), we opted for setting the values of these parameters following a "curve-fitting" procedure: First, we set a smooth J curve to represent a "target" hazard function consistent with the empirical evidence of J-shaped devaluation probabilities -- this target function is the same exogenous hazard rate function used in Mendoza and Uribe (1997), which featured an initial devaluation probability at about 0.4, falling to zero in about 12 quarters and raising to 0.8 prior to the collapse. Second: we set the algorithm that solves the equilibrium of the model to search for values of $B$ and $\Gamma$ that yield the closest approximation, in the Euclidean sense, to the target hazard rate function. This approach yields the following parameter structure: $B=0.17$ and $\Gamma=-2.9$. Note that this procedure does not impose any specific restrictions on the two parameters. Still, the solution yields B $>0$, which is consistent with the view that the probability of devaluation increases as reserves fall. The value of $\Gamma$ reflects the initial odds of a devaluation at the time the currency peg is introduced, given the initial gap between observed lagged reserves and their critical level.

\subsection{Benchmark Simulation and Mexico's Stylized Facts}

The solutions for state-contingent macroeconomic dynamics and the endogenous devaluation probabilities produced by the benchmark calibration are plotted in Figure 1. The 
equilibrium dynamics plotted in this figure correspond to state-contingent allocations measured as percent deviations from the deterministic pre-stabilization steady state. The continuous lines represent the dynamic equilibrium paths under the assumption that the currency peg continues, and the dotted lines indicate the allocations to which the variables shift on impact when a devaluation occurs.

Since the model was calibrated to capture roughly the policy stance of Mexico's 19871994 exchange-rate-based stabilization, it is instructive to review briefly the cyclical dynamics of the Mexican economy during that period following the discussion in Mendoza and Uribe (1997). From the first quarter of 1988 to the last quarter of 1994, Mexico's real exchange rate appreciated by 35.4 percent -- recall the Mexican plan was announced in December of 1987 but the exchange rate was fixed two months later. The deviations from trend in GDP, investment, GDP, and private consumption widened considerably during 1988-92, but in 1993 all three fell below trend, in line with the common feature of exchange-rate-based stabilizations that recessions often predate currency collapses. The fluctuations in real variables were also very large. At the peak of the cycle in 1992, the deviations from trend in GDP and consumption were about 6 percentage points higher, and the one for investment was 15 percentage points higher, than at the cyclical minimum reached just before the beginning of the program in early 1987 . The boom in private consumption and the appreciation of the real exchange rate were nearly perfectly positively correlated until 1993, when consumption began to slow down but the real appreciation continued. Mexico's external imbalances worsened at a steady rate until the current account deficit reached 8 percent of GDP just before the devaluation at the end of 1994. 
The results of the benchmark simulation show that the model is roughly consistent with these stylized facts. In particular, the model recreates boom-recession cycles in GDP, consumption, and investment with recessions that pre-date the devaluations. Aggregate and sectoral consumption move together with the real exchange rate for most of the duration of the stabilization plan, suggesting that the model can explain the high correlation between the real exchange rate and consumption that lies behind the price consumption puzzle. The trade balance worsens markedly on the early stages of the peg, and then remains stable until it improves in a sudden jump that coincides with the collapse of the currency.

The endogenous monetary dynamics of the model are in line with the predictions typical of a model of balance-of-payments crises. Central bank foreign reserves increase initially, as the decline in the velocity of circulation that occurs in the early stages of the peg reflects the remonetization of the economy in response to the reduction in the nominal interest rate and the boom in real economic activity. ${ }^{14}$ This re-monetization plays a key role in allowing the model to mimic the initial declining path observed in empirical estimates of devaluation probabilities. After this initial stage, reserves decline gradually and then rapidly until they are finally depleted in a sudden jump to their critical level just before the collapse of the peg. This pattern in turn produces an endogenous time path of devaluation probabilities that, after the initial declining stage, begins to increase gradually and then rapidly, thus approximating the $\mathrm{J}$ shape of devaluation probabilities identified in empirical research.

${ }^{14}$ Typically, models of currency crises do not focus on this initial build up of reserves because they start from an existing fixed exchange rate, while our policy experiment starts with a switch from a floating exchange rate to a fixed exchange rate. 
In comparing the model's predictions to Mexican data, we acknowledge that Mexico's business cycles are caused by several factors in addition to the distortions resulting from currency risk, which is the only driving force of business cycles in the model we proposed. In Mendoza and Uribe (1997) we addressed this issue by trying to isolate the potential contribution of exchange-rate uncertainty from the effects of other sources of business cycles using a VAR model proposed by Calvo and Mendoza (1996). We used the interest-rate differential between Mexican and U.S. treasury bills as a measure of the probability of devaluation and default, and found that this differential explains about 40 percent of the variability of macroeconomic aggregates and the real exchange rate over 24 quarters. ${ }^{15}$ Taking into account the total magnitude of the observed fluctuations, this suggests that an ideal simulation of our model should not be able to account for more than an 18 percent real appreciation, consumption and GDP booms in excess of 2 percent, and investment booms in excess of 5 percent. Hence, the 14 percent real appreciation produced by this model is less than 1/2 the full real appreciation observed in México during 1988-94, but is close to the 18 percent appreciation measured using the VAR.

We also acknowledge that in our effort to follow Mundell's analysis, we specified a functional form for the formulation of expectations of devaluation that may be too restrictive in the light of existing empirical evidence. Klein and Marion (1997), Frankel and Rose (1996) and Kaminsky and Reinhart (1996) all show that the appreciation of the real exchange rate is a robust predictor of the collapse of fixed exchange rates even when the information provided by central

${ }^{15}$ Note, however, that the interest differential is almost perfectly correlated with the Mexican interest rate, and the latter was influenced by sterilized intervention of large capital flows during 1990-94. Thus, the differential is at best a noisy measure of the "market" expectations of the sustainability of the peg. 
bank foreign reserves is taken into account. Moreover, Klein and Marion also show that even if both reserves and the real exchange rate are used as predictors, the duration of the peg per se is also a robust predictor of currency crashes. In line with this finding, we found that simulations of the model in which a linear term in $t$ is introduced into the functional form of $z_{t}$ produce a closer fit to the J-curves estimated in the data than the basic specification set in equation (5). Thus, we did not expect our basic specification to mimic closely the Mexican data, but were still surprised by its ability to approximate some of their key features.

\subsection{Effects of the "Confidence of Speculators:" Revisiting Mundell's Findings}

The last set of numerical exercises examines the implications of altering the responsiveness of speculators to observed changes in reserves (i.e. altering the value of B) with the aim of exploring the predictions of the model for an experiment analogous to the one conducted by Mundell (1960). We conduct this analysis in two stages. First, we simulate the model under alternative values of $\mathrm{B}$, keeping the values of all other parameters constant, and compare the results to those of the benchmark model. Second, we allow B to vary as in the first case, but we also allow the government to put up a "fight" for its foreign reserves by undertaking for each value of $B$ the fiscal adjustment (i.e. the required changed in $\kappa$ ) that is necessary for the currency peg to have a chance to last a maximum of $J$ periods.

The first experiment, in which B is changed while maintaining unaltered the rest of the structure of the model, sheds some light on the model's predictions regarding the connection between the stance of fiscal and exchange-rate policies and the occurrence of endogenous speculative attacks that lead to a currency collapse before date $J$. Figure 2 plots the hazard function, the reserves-to-GDP ratio, GDP, and the real exchange rate for the benchmark case and 
for cases in which the value of B is 10, 20 and 40 percent larger than in the benchmark parameterization. The horizontal dotted lines in the plots of the reserves-to-GDP ratio indicate the values of $R_{d} / Y_{0}$ and $(R / Y)^{\text {crit }}$, both of which are constant across the simulations.

The plots in Figure 2 show that as speculation strengthens, the same stance of fiscal and exchange rate policies results in currency collapses that occur sooner than in the benchmark case. When speculation has strengthened to the point that B is 40 percent higher than in the benchmark case (panel d), the devaluation probability remains very high throughout the duration of the peg, and the peg itself cannot last more than 4 quarters. Foreign reserves decline very rapidly and the cyclical increases in real output and the real exchange rate are smaller than in the benchmark simulation. Naturally, the opposite results would obtain if we tried reducing B instead of increasing it -- as speculation becomes weaker, the same stance of fiscal policy would result in currency pegs that could be maintained for more than $J$ periods (if we relaxed the assumption that at $J$ the currency must collapse with probability 1$)$.

A higher value of B brings forward the date of a speculative attack in part simply because changing this exogenous parameter implies that agents assign a higher probability to the collapse of the currency peg for any given fall in the reserves-to-GDP ratio. There is in addition an endogenous channel that accelerates the collapse by altering the dynamics of reserves. As explained in Section 3, the probability of devaluation is a distortion that affects the real and monetary sectors of the economy. This distortion can be approximated by the risk premium reflected in the gap between the domestic opportunity cost of holding money, $i_{t} /\left(1+i_{t}\right)$, and the opportunity cost that would rule in the absence of the distortion, which would be identical to the world interest factor $r * /\left(1+r^{*}\right)$. It is straightforward to show that as $z_{t}$ rises the risk premium 
rises because arbitrage requires a higher domestic interest rate when the probability of devaluation increases. Moreover, it is also easy to show that, in this setting with incomplete markets and risk-averse agents, a devaluation implies an adverse shock to wealth that magnifies the risk premium. As the domestic interest rate rises driven by these two effects, the velocity of circulation of money rises and the demand for money falls, thereby altering the dynamics of reserves. The plots in Figure 2 show that, as a result, an increase in B leads to a smaller initial surge in reserves -- or even no increase at all as in the case of panel (d) -- and a more rapid depletion of reserves after the initial surge.

The results for the second experiment, where B and $\kappa$ are allowed to vary, are plotted in Figure 3. Note that $\kappa$ is falling in each case so that larger cuts in government outlays during the stabilization plan ensure that the ratio of reserves to GDP does not reach the critical level until the same date as in the benchmark scenario. Clearly, this response of the government neutralizes the effects of modest variations in B and yields results roughly similar to the benchmark case. However, if $\mathrm{B}$ is too large (as in panel (d)), the logistic functional form of $z_{t}$ produces probabilities of devaluation that are virtually equal to 1 despite the dynamics of reserves. Hence, even tough foreign reserves reach the critical level at $t=J-1$, the results are similar to the case in which government policy is not tightened an reserves reach the critical level much earlier.

Figures 2 and 3 can now be examined jointly to study the implications of an experiment similar to the one in Mundell (1960), in which the government tightens policy in an effort to defend the peg as speculation grows stronger. There is a nontrivial difference because Mundell focused on the case in which this is done by the central bank adopting measures to increase the nominal interest rate under conditions of imperfect capital mobility. This is ruled out by the 
assumption of perfect capital mobility in our model, and hence we consider instead the adjustment to fiscal policy as the closest approximation. As mentioned in the introduction, Mundell showed that macroeconomic dynamics would vary widely depending on the particular static parameters that measured the "speeds of response" of speculators and policy-makers, and that dynamics could even turn from stable to unstable, or from cyclical to asymptotic.

Comparing Figures 2 and 3, we find that in our model, just like in Mundell's, the relative response of speculators and the government is critical for determining macroeconomic dynamics. These figures represent two extreme cases of the government's response. Figure 2 illustrates cases in which the government does not respond and simply keeps $\kappa$ at the benchmark level of 13.3 percent, while Figure 3 reports cases in which the government responds fully and hence reduces $\kappa$ to protect its foreign reserves. Comparing panels (b) and (c) of the two figures we note that the cyclical dynamics of GDP and the real appreciation differ sharply between these two extreme cases. While none of these experiments show the oscillatory dynamics that Mundell argued could exist for some combinations of speed-of-response parameters, we did find other rare examples in which equilibrium dynamics could display oscillations (for instance in the case in which $\Gamma=0, B=-0.17$ and $\kappa=0.234)$. Hence, we conclude that Mundell's findings are roughly consistent with the quantitative predictions of our model.

\section{Conclusion}

This paper re-examined Mundell's model of currency speculation in the light of modern international macroeconomics. In particular, the paper derived the quantitative predictions of an intertemporal, general equilibrium model in which rational speculators form probabilities of devaluation on the basis of the observed evolution of the stock of central bank foreign reserves. 
The model represents a small open economy with perfect capital mobility, but with incomplete contingent-claims markets.

In this model, exchange-rate uncertainty is a monetary distortion that can induce large real economic fluctuations. Market incompleteness implies that devaluation probabilities driven by the dynamics of foreign exchange reserves, as Mundell envisaged, introduce significant distortions on wealth and on the intertemporal and intratemporal relevant relative prices faced by economic agents. As a result, the model is capable of rationalizing some of the key empirical regularities of exchange-rate-based stabilizations. In particular, the model is consistent with large real appreciations, large external deficits, booms in output and absorption followed by recessions that predate currency collapses, and a high positive correlation between the real exchange rate and domestic absorption for the duration of currency pegs. The model is also relatively successful in producing endogenous devaluation probabilities that capture the J-shaped nature of devaluation probabilities that have been identified in actual data by several authors.

Our analysis shows that, for a given policy setting, endogenous speculative attacks occur earlier in economies where investors are more sensitive to observed changes in foreign reserves. This is in part because they simply grow more anxious for a given change in reserves, but also because in equilibrium their increased sensitiveness results in a higher premium on the domestic interest rate that magnifies the distortions of the model and accelerates the depletion of reserves. The simulations also produce results consistent with the findings of Mundell's (1960) analysis of speculators and policy-makers engaged in a "fight" over the central bank's foreign reserves. Mundell showed that, depending on the sensitiveness of investors to observed changes in reserves relative to the policy response of the government, the dynamics of adjustment could be 
stable or unstable, oscillatory or asymptotic. In our model equilibrium dynamics are also very sensitive to increases in the sensitiveness of speculators that are matched by a tightening of fiscal policy intended to protect foreign reserves.

The policy lessons that can be drawn from this exercise are interesting. First, we note that in this model losses of foreign reserves, real appreciation and external deficits are not exogenous triggers of balance-of-payments crises. What lies behind these crises is the lack of confidence of the private sector expressed in the formation of devaluation probabilities. Second, the cyclical dynamics of exchange-rate-based stabilizations and the collapse of fixed exchange rates do not need to result from sudden changes in fiscal or monetary policies. We showed that a model calibrated to reflect Mexico's tight policies between 1987 and 1993 still yields large real appreciation and large trade deficits, and that the currency crises may occur sooner or later depending on the sensitiveness of the private sector's confidence to observed changes in foreign reserves. Third, since crises in our model can be produced by lack of confidence and confidence is linked to foreign reserves, Mundell's (1960) key policy recommendation remains valid today: "an effective system of international payments based on fixed exchange rates must be one which provides a reasonably high degree of international liquidity" (p. 246). As Calvo and Mendoza (1996) noted, however, this "reasonable high degree of international liquidity" is likely to be a very large figure in today's global economy. 


\section{References}

Blanco, Herminio, and Peter M. Garber (1986), "Recurrent Devaluation and Speculative Attacks on the Mexican Peso," Journal of Political Economy, v. 94, p. 148-166.

Calvo, Guillermo A. (1986), "Temporary Stabilization: Predetermined Exchange Rates," Journal of Political Economy, v. 94, pp.1319-1329.

(1987), "Balance of Payments Crises in a Cash in Advance Economy," Journal of

Money, Credit and Banking, v. 19, pp. 19-32. , and Allan Drazen, (1993) "Uncertain Duration of Reform: Dynamic Implications,"

Working Papers in International Economics No. WP 4, Center for International Economics, University of Maryland.

, and Enrique G. Mendoza, (1996) "Mexico’s Balance-of-Payments Crisis: A Chronicle of

a Death Foretold," Journal of International Economics, Vol. 41 (3-4) pp. 235-264.

Frankel, Jeffrey A. Frankel and Andrew K. Rose, "Currency Crashes in Emerging Markets: An

Empirical Treatment," Journal of International Economics, Vol. 41, (3-4) pp. 351-367.

Goldberg, Linda S. (1994), "Predicting Exchange Rate Crises: México Revisited," Journal of

International Economics, v. 36, pp. 413-430.

Greenwood, Jeremy (1983), "Expectations, the Exchange Rate and the Current Account,"

Journal of Monetary Economics, vol. 12, pp. 543-569.0 , (1984), "Non-traded Goods, the Trade Balance, and the Balance of Payments,"

Canadian Journal of Economics, vol. 17, pp. 806-823

Helpman, Elhanan and Assaf Razin (1987), "Exchange Rate Management: Intertemporal Tradeoffs," American Economic Review, vol. 77, pp.107-123. 
Kamin, Steven and John H. Rogers (1996), "Monetary Policy in the End-Game to ExchangeRate-Based Stabilizations: The Case of México," Journal of International Economics.

Kaminsky, Graciela and Carmen M. Reinhart (1996), "The Twin Crises: The Causes of Banking and Balance-of-Payments Problems," International Finance Discussion Paper, Division of International Finance, Board of Governors of the Federal Reserve System.

Kiguel, Miguel and Nissan Liviatan (1992), "The Business Cycle Associated with Exchange Rate Based Stabilization," World Bank Economic Review, vol. 6., pp. 279-305.

Kimbrough, Kent P. (1986) "The Optimum Quantity of Money Rule in the Theory of Public Finance Journal of Monetary Economics, 18(3), 277-84.

King, Robert G., Charles I. Plosser, and Sergio T. Rebelo (1988), "Production, Growth, and Business Cycles," Journal of Monetary Economics, vol. 21, pp. s126-s150.

Klein, Michael W. and Nancy P. Marion, (1997) "Explaining the Duration of Exchange-Rate Pegs," Journal of Development Economics, v. 54, pp. 387-404.

Krugman, Paul, (1979), "A Model of Balance-of-Payments Crises," Journal of Money, Credit, and Banking, vol. 11, pp.311-325.

Mendoza, Enrique G. (1995), "The Terms of Trade, the Real Exchange Rate and Economic Fluctuations," International Economic Review, vol. 36, pp. 101-137. , and Martin Uribe (1997), "The Syndrome of Exchange-Rate-Based Stabilizations and the Uncertain Duration of Currency Pegs," Discussion Paper Series, Research Department, Federal Reserve Bank of Minneapolis, Minneapolis, MN. and Linda L. Tesar (1998), "The International Ramifications of Tax Reforms: Supply Side Economics in a Global Economy,: American Economic Review, vol. 88, no.1, pp. 226-245. 
Mundell, Robert A. "The Monetary Dynamics of International Adjustment under Fixed and Flexible Exchange Rates," Quarterly Journal of Economics, v. LXXIV, no. 2, May 1960, pp.227-257.

Obstfeld, Maurice (1986), "Rational and Self-Fulfilling Balance-of-Payments Crises," American Economic Review, vol. 76, pp. 72-81. , (1995), "International Currency Experience: New Lessons and Lessons Relearned," unpublished manuscript, Department of Economics, University of California Berkeley. Rebelo, Sergio T, and Carlos A. Végh, (1996), "Real Effects of Exchange-Rate-Based Stabilization: An Analysis of Competing Theories," NBER Macro Annual, National Bureau of Economic Research, Cambridge: MA.

Reinhart Carmen M. and Carlos A. Végh (1995), "Nominal Interest Rates, Consumption Booms, and Lack of Credibility: A Quantitative Examination," Journal of Development Economics, Uribe, Martin (1997a), "Exchange-Rate-Based Inflation Stabilization: The Initial Real Effects of Credible Plans," Journal of Monetary Economics, 39(2), 197-221. (1997b), "Habit Formation and the Comovement of Prices and Consumption During Exchange-Rate-Based Stabilization Programs," Working paper, International Finance Division, Board of Governors of the Federal Reserve System, Washington, DC, April, 1997. Végh, Carlos A. (1992), "Stopping High Inflation: An Analytical Overview," IMF Staff Papers, 39, 626-695. 


\section{Figure 1: MACROECONOMIC DYNAMICS OF AN EXCHANGE-RATE-BASED STABILIZATION OF UNCERTAIN DURATION WITH ENDOGENOUS HAZARD FUNCTION*}
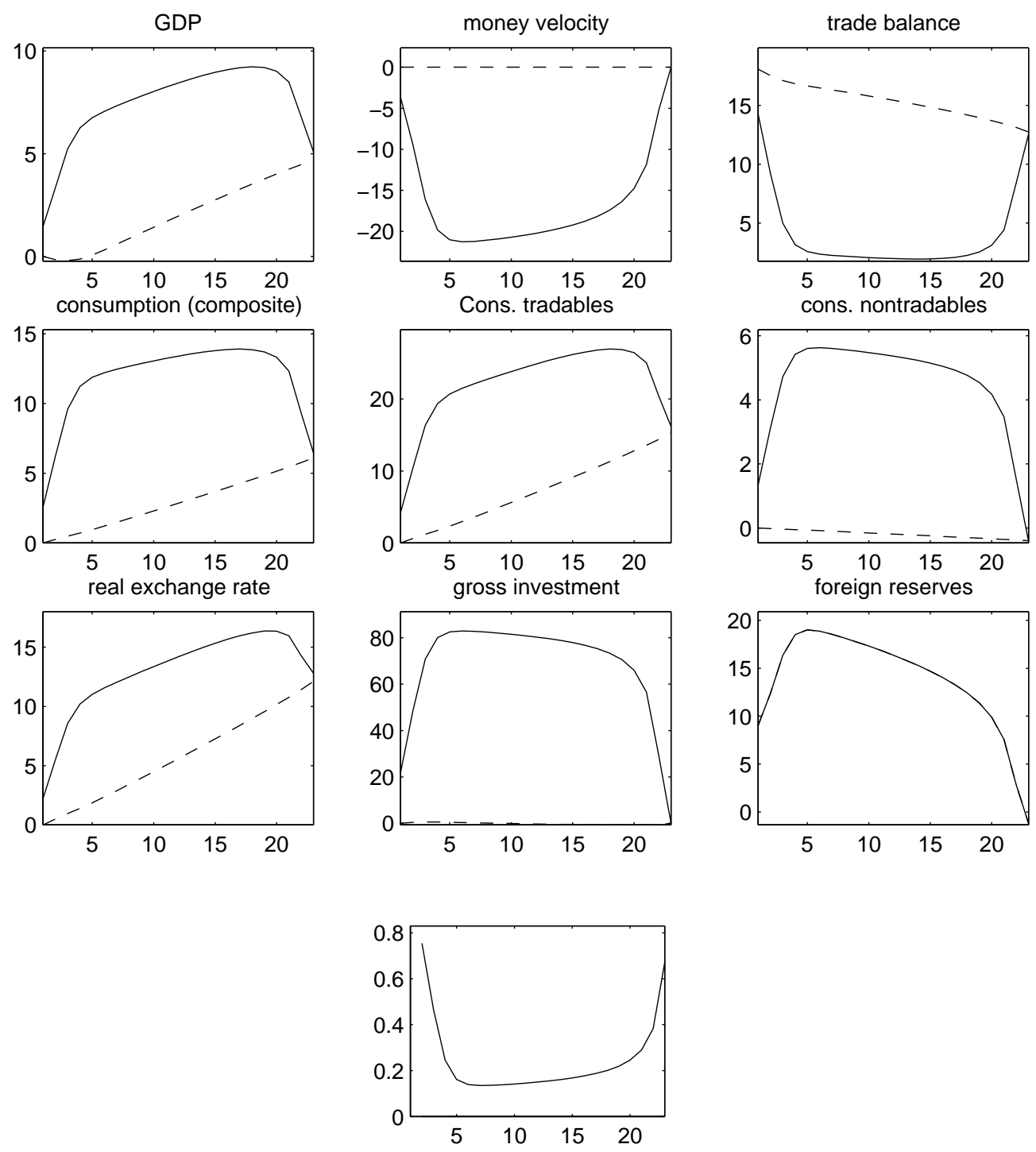

hazard function

* All variables, except $N X_{t} / Y_{t}$, are expressed in percentage deviations from their pre-stabilization steadystate. Solid lines denote pre-collapse values and broken lines at-collapse values. The hazard function takes the form $z_{t} \equiv \operatorname{Pr}\left(e_{t+1}=e^{h} \mid e_{t}=0\right)=\exp \left(w_{t}\right) /\left(1+\exp \left(w_{t}\right)\right)$, where $w_{t}=\Gamma+B /\left(\frac{R_{t-1}^{L}}{4 Y_{t-1}^{L}}-\left(\frac{R_{t-1}^{L}}{4 Y_{t-1}^{L}}\right)^{c r i t}\right)$, with $B=.17$ and $\Gamma=-2.9$. 
Figure 2

Sensitivity analysis: Varying the sensitivity of the hazard function to changes in foreign reseves

(a) Benchmark parameterization: $B=0.17, \Gamma=-2.93$
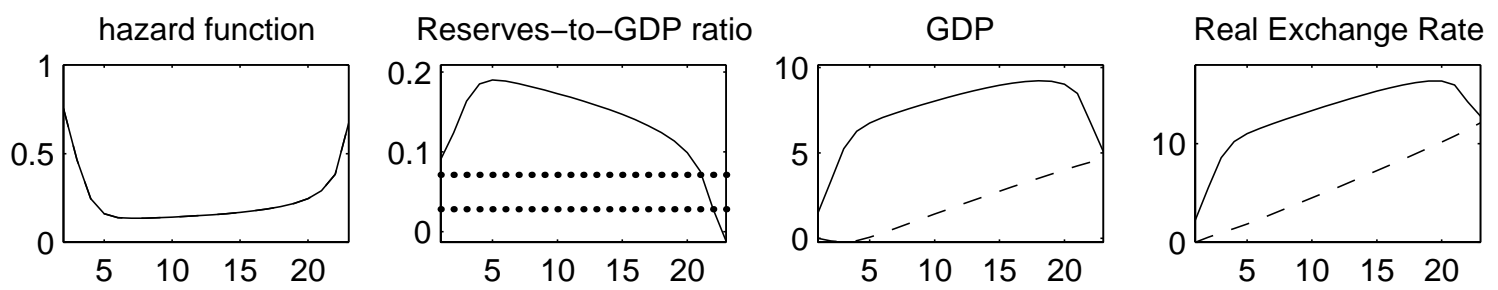

(b) $B=1.1 \cdot B^{\text {benchmark }}$
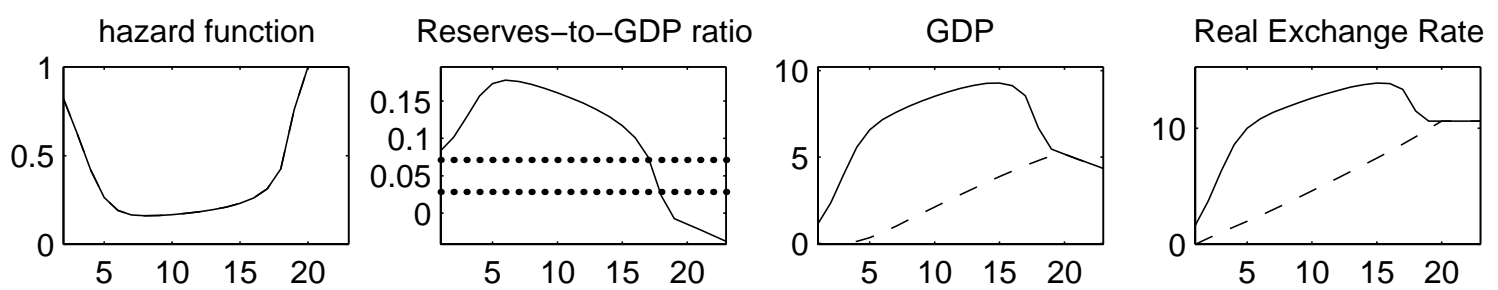

(c) $B=1.2 \cdot B^{\text {benchmark }}$
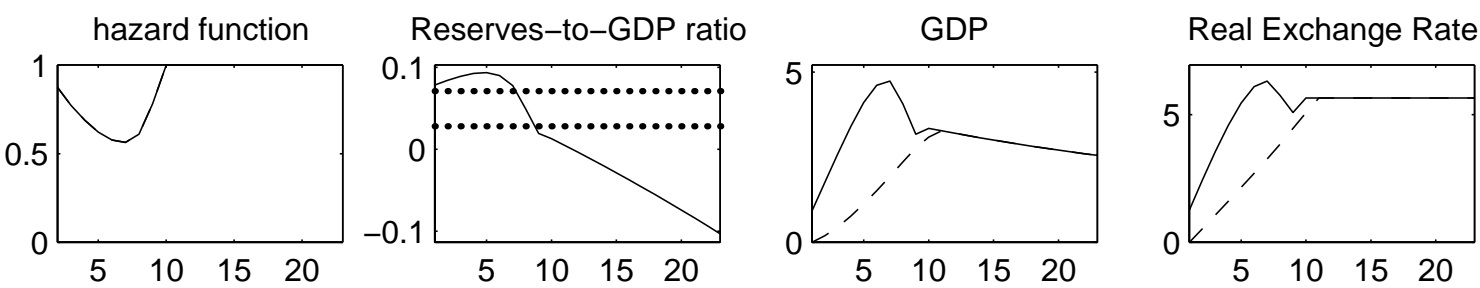

(d) $B=1.4 \cdot B^{\text {benchmark }}$
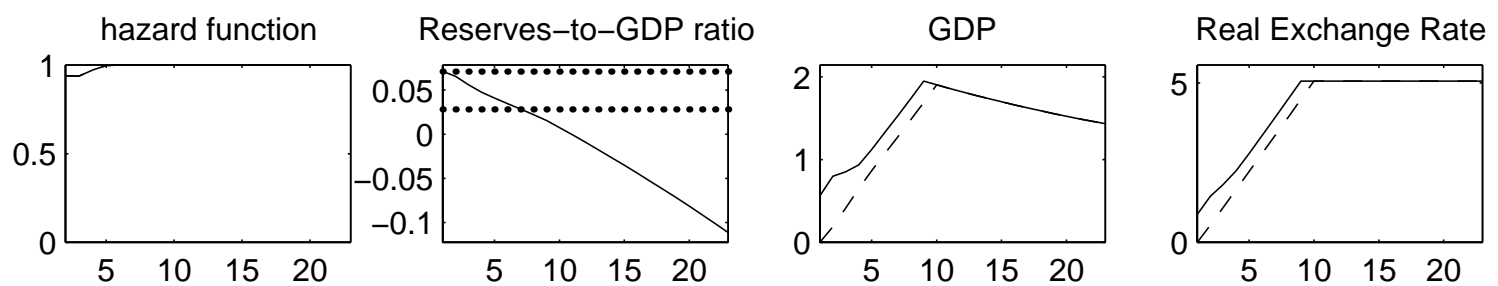

Note: The dotted lines on the second column denote the initial and critical reserve-to-GDP ratios $\left(R_{0} / Y_{0}\right.$ and $\left.(R / Y)^{c r i t}<R_{0} / Y_{0}\right)$. The solid lines on the second and third columns show pre-collapse values and the broken lines show values at the date of collapse. GDP and the real exchange rate are measured in percentage deviations from their respective pre-stabilization steady states. 
Figure 3

Sensitivity analysis: Varying the sensitivity of the hazard function to changes in foreign reseves $(B)$ and the degree of fiscal adjustment $(\kappa)$

(a) Benchmark parameterization: $B=0.17, \Gamma=-2.93$, and $\kappa=0.13$
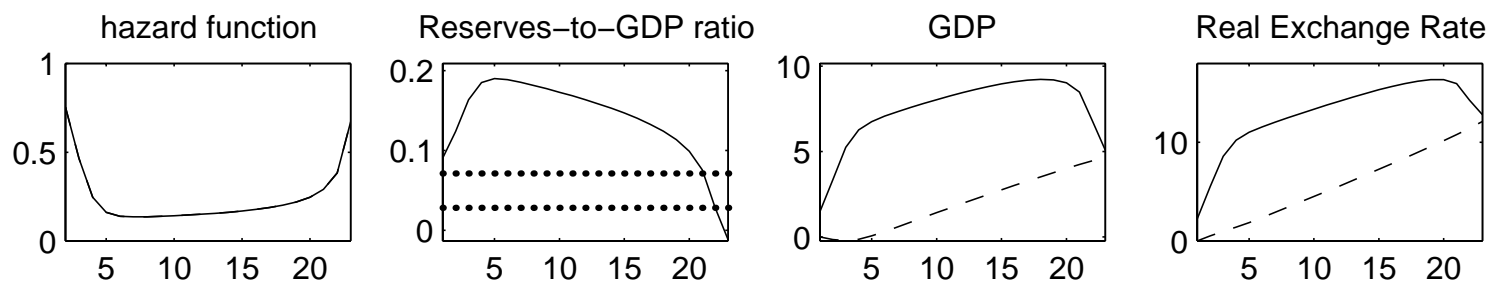

(b) $B=1.1 \cdot B^{\text {benchmark }}, \Gamma=-2.93$, and $\kappa=0.12$
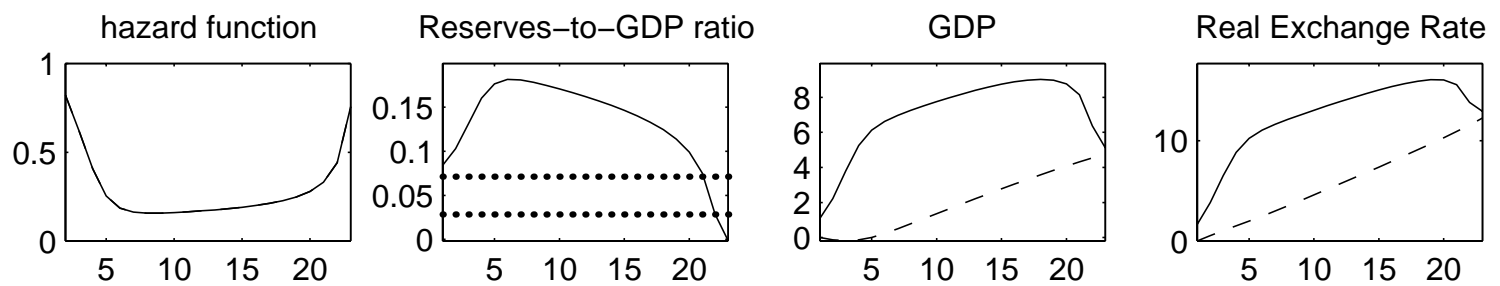

(c) $B=1.2 \cdot B^{\text {benchmark }}, \Gamma=-2.93$, and $\kappa=0.11$
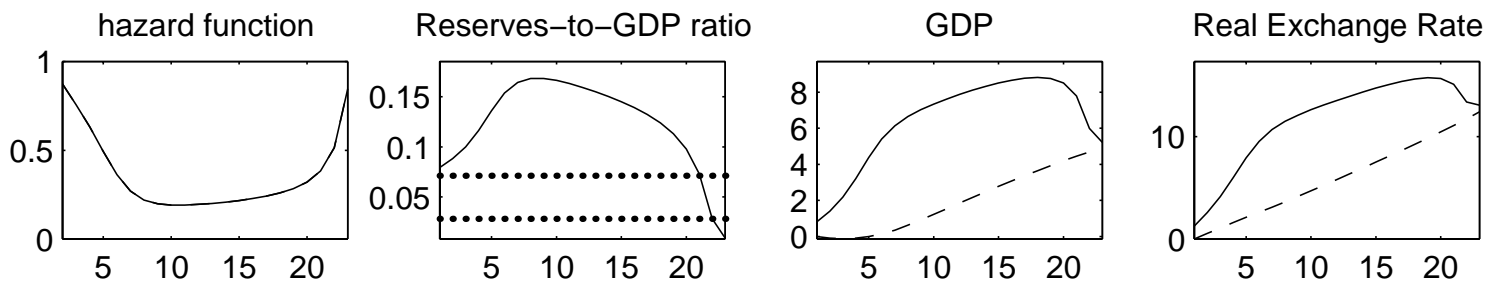

(d) $B=1.4 \cdot B^{\text {benchmark }}, \Gamma=-2.93$, and $\kappa=0.07$
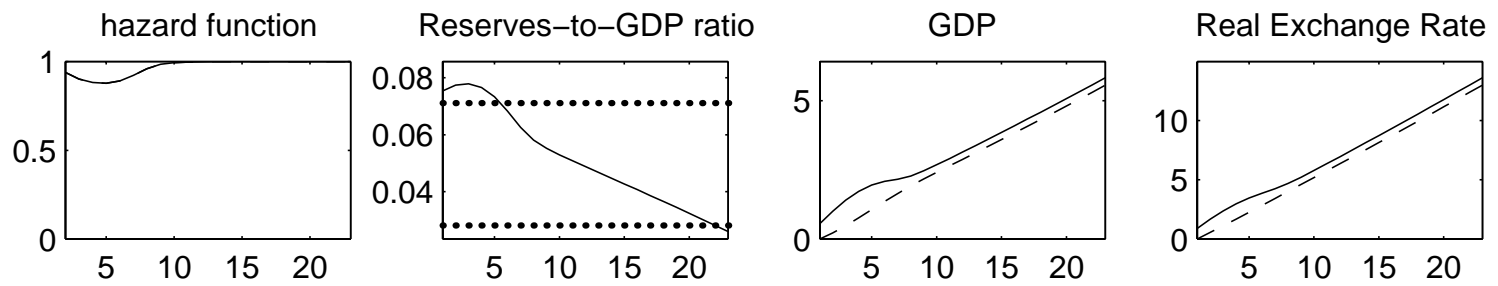

Note: In each row, the adjustment in the parameter $\kappa$ guarantees that if the program survives until period $J-2$, then the reserves-to-GDP ratio reaches its critical value of 2.8 percent at that date. The dotted lines on the second column denote the initial and critical reserve-to-GDP ratios $\left(R_{0} / Y_{0}\right.$ and $\left.(R / Y)^{c r i t}<R_{0} / Y_{0}\right)$. The solid lines on the second and third columns show pre-collapse values and the broken lines show values at the date of collapse. GDP and the real exchange rate are measured in percentage deviations from their respective pre-stabilization steady states. 